\section{E-138 SAFETY AND FEASIBILITY OF TRANSRADIAL APPROACH FOR CERVICAL CAROTID STENTING FOR TREATMENT OF CAROTID-ARTERY STENOSIS}

${ }^{1}$ E Almallouhi* ${ }^{*}{ }^{2} \mathrm{~S}$ Al kasab, ${ }^{3} \mathrm{P}$ Jabbour, ${ }^{4} \mathrm{M}$ Gooch, ${ }^{3} \mathrm{~A}$ Sweid, ${ }^{4} \mathrm{~N}$ Chalouhi, ${ }^{5} \mathrm{~S}$ Chen, ${ }^{5} \mathrm{Y} \mathrm{Li}$, ${ }^{6} \mathrm{E}$ Peterson, ${ }^{6} \mathrm{D}$ Yavagal, ${ }^{5} \mathrm{R}$ Starke, ${ }^{2} \mathrm{~A}$ Spiotta. ${ }^{1}$ Medical University of South Carolina, Charleston, SC; ${ }^{2}$ Neurosurgery, Medical University of South Carolina, Charleston, SC; ${ }^{3}$ Neurosurgery, Jefferson University, Philadelphia, PA; ${ }^{4}$ Jefferson University, Philadelphia, $P A$; ${ }^{5}$ Neurosurgery, University of Miami, Miami, FL; ${ }^{6}$ University of Miami, Miami, FL

10.1136/neurintsurg-2020-SNIS. 170

Background Traditionally, cervical carotid artery stenting is done through transfemoral or transcarotid approach. However, access site bleeding remains a significant challenge in both techniques, with a rate of about $4 \%$ in recent studies. In this study, we explore the feasibility of using transradial approach for cervical carotid stenting as a potential alternative.

Methods We collected data from the prospectively maintained registries of 6 centers in the United States to include consecutive patients who underwent carotid stenting for treatment of symptomatic carotid-artery stenosis using transradial approach from October 2018 until June 2019. Collected data included baseline characteristics, procedural variables, whether there was a crossover to transfemoral access, and complications. Our primary outcome was the complication rate related to the access site.

Results A total of 19 patients were included in this study. Mean age was $68.6( \pm 8)$, and $5(26.3 \%)$ were females. The right radial artery access was used in all cases. Stenting of the right cervical internal carotid artery was done in 15 (78.9\%) of the cases. Regarding the antispasmodic regimen used, Verapamil was used in 2 cases, Nitroglycerin was used in 6 cases, and a combination of both was used in 11 cases. Between 2000-5000 units of heparin were administered intraarterially or intravenously immediately after obtaining the access. A 6-French sheath was used in 13 cases, a 7 French sheath in 3 cases, and in 3 cases, the guide catheter (AXS Infinity, Stryker, USA) was exchanged over a 7-French sheath. Regarding guide catheters used, Benchmark (Penumbra, USA) was used in 14 cases, AXS Infinity in 3 cases, and Envoy (Codman Neuro, USA) in 2 cases. Mean contrast dose required was $93.3( \pm 48.4)$, radiation exposure was 14603 $( \pm 26118) \mathrm{mGy}$, and procedure duration was $24.6( \pm 14.2)$ min. None of the included patients had a complication related to access site, and only one patient required a crossover to transfemoral approach because of a device-related complication.

Conclusion Transradial approach is a feasible and safe option for cervical carotid stenting. The complication rate in our study is lower than previously reported numbers for transfemoral and transcarotid carotid stenting, but larger-scale studies are needed to confirm our findings.

Disclosures E. Almallouhi: None. S. Al kasab: None. P. Jabbour: 2; C; Medtronic and MicroVention. M. Gooch: None. A. Sweid: None. N. Chalouhi: None. S. Chen: None. Y. Li: None. E. Peterson: None. D. Yavagal: 2; C; Medtronic Neurovascular, Cerenovus, Rapid Medical and Neuralanalytics. R. Starke: 2; C; Penumbra, Abbott, Medtronic, InNeuroCo and Cerenovus. A. Spiotta: 1; C; Penumbra. 2; C; Penumbra, Stryker, Cerenovus, Terumo.

\section{E-139 ENDOVASCULAR TREATMENT OF ANTERIOR CRANIAL FOSSA FISTULAS: THE SIGNIFICANCE OF RETROGRADE TRANSVENOUS APPROACH}

J Mejia*, J Gutierrez, O Vargas, V Torres, M Patiño, B Pabon. Neurointevencionismo, AngiTeam, Medellin, COLOMBIA

\subsection{6/neurintsurg-2020-SNIS.171}

Purpose Anterior cranial fossa (ACF) Dural arteriovenous fistulae (DAVFs) are infrequent lesions, and usually treated by surgical disconnection or endovascular embolization via the ophthalmic artery. The retrograde transvenous route is a rarely used approach. This paper describes our experience in terms of safety and efficacy of embolization of DAVF of the anterior cranial fossa with different embolic agents through the venous side.

Materials and Methods Between September 2016 and January 2020 a retrospective review was performed. A total of 10 patients with DAVF of the anterior cranial fossa managed with embolization through the venous side with Onyx/PHIL were selected. Information on demography, symptoms and signs, angiographic examinations, interventional treatments, angiographic and clinical results, and follow-up was collected and analyzed.

Results Nine patients were included in this study, patients were between 14 and 79 years old (mean 45.6). Six primarily presented with intracranial hemorrhage. All fistulas were fed by the bilateral ethmoidal arteries arising from the ophthalmic artery and by the anterior branch of the middle meningeal artery. One case with history of type D CCF. The abnormal shunt drained into the superior sagittal sinus with interposition of the cortical veins in all nine patients. All of the cases had high-grade Cognard classifications (III-IV). 4(44\%) patients had been treated via trans arterial embolization (TAE) via the AEA of the OA. All cases were treated via transvenous embolization (TVE), 8 of $9(88 \%)$ were treated with the trans-SSS approach. Complete angiographic cure was achieved in all patients, without postprocedural complications. There were nearly no symptoms among the patients during follow-up.

Conclusion Embolization of DAVF of the anterior cranial fossa via retrograde using transvenous approach with embolic agents is safe, effective, and a good choice for management of this rare condition. Endovascular treatment (EVT) can completely obliterate the fistula point and correct the venous shunting. More cases are needed to verify these findings.

Disclosures J. Mejia: None. J. Gutierrez: None. O. Vargas: None. V. Torres: None. M. Patiño: None. B. Pabon: None.

\section{E-140 EFFECT OF BODY MASS INDEX ON PERIOPERATIVE OUTCOMES IN MINIMALLY INVASIVE TRANS-KAMBIN POSTERIOR OBLIQUE LATERAL LUMBAR INTERBODY FUSION VERSUS OPEN FUSIONS: A MULTIVARIANT ANALYSIS}

H Abbasi*. Neurosurgery, Inspired Spine, Alexandria, MN

\subsection{6/neurintsurg-2020-SNIS.172}

Background Obesity is an increasing public health concern associated with increased perioperative complications and 